\title{
Pengembangan Model Kebijakan Pelayanan Gratis di Puskesmas
}

\author{
The Development of Free Health Care Policy Model in Puskesmas
}

\author{
Iskandar Syah* Eryati Darwin** Hafni Bachtiar** Vera Pujani**
}

*Dewan Perwakilan Rakyat Daerah Kota Padang, **Fakultas Kedokteran Universitas Andalas Padang

\begin{abstract}
Abstrak
Dengan adanya Peraturan Daerah Nomor 05 tahun 2009 lahirlah kebijakan pelayanan kesehatan gratis di kota Padang. Pelayanan kesehatan gratis ini merupakan dukungan pemerintahan kota kepada warganya untuk menyadari bahwa kesehatan merupakan kebutuhan dasar dan kebijakan ini mendapat dukungan dari Bazda (Badan Zakat Daerah). Tujuan dari penelitian ini adalah untuk menganalisis model pengembangan kebijakan pelayanan kesehatan gratis di kota Padang. Penelitian ini dilakukan dengan menggunakan pendekatan kualitatif dan kuantitatif. Data kualitatif diperoleh dari Dinas Kesehatan Kota Padang. Sedangkan data kuantitatif diperoleh melalui wawancara dan focus group disscussion (FGD). Enam pimpinan puskesmas dan tenaga kesehatan merupakan informan yang diwawancarai untuk mengidentifikasi variabel yang diselidiki. Pimpinan pemerintahan yang terkait dengan kebijakan ini juga dilibatkan untuk memperoleh data yang dibutuhkan, sedangkan kepuasan pasien tentang pelayanan kesehatan gratis ini diperoleh melalui FGD. Analisis terhadap semua data yang diperoleh dari informan dalam penelitian ini dilakukan secara multicase analisis. Penelitian ini menemukan bahwa pengembangan model kebijakan pelayanan kesehatan gratis yang ditawarkan adalah model pelayanan yang dapat memberikan manfaat maksimal bagi semua pihak yang terlibat termasuk pasien, puskesmas dan tenaga kesehatan.

Kata kunci: Kebijakan, pelayanan kesehatan gratis, puskesmas
\end{abstract}

\footnotetext{
Abstract

According to Peraturan Daerah Nomor 05 tahun 2009 toward the free health service in Padang city implied that the free service of health care was driven by the consideration of the city government as basic public needs and financially suported by Bazda (Badan Zakat Daerah). The objective of the study is to analyze the development of free health care policy model in Padang. The study was conducted by using quatitative and qualitative data. The quantitative data was obtained from the health agency office in Padang. Hence the qualitative data was obtained through interview and fo-
}

cus group discusion (FGD). The six puskesmas managers and health workers as the research informant were interviewd to identify the investigated variable. The related goverment leaders also were involved to make data collection comprehensivelly. In the meantime, satisfaction patients related to service delivery were investigated using FGD. All informant obtained were transcriped as picture for this research in the multicase analysis. This study found that the model development of free service policy offered is a model of service that can provide the maximum benefits for all aspects involved including patients, health centers, and health professionals.

Keywords: Policy, free health care, primary health care

\section{Pendahuluan}

Peraturan Daerah Nomor 05 tahun 2009 tentang pelayanan kesehatan gratis di Kota Padang mencerminkan keinginan pemerintah kota mendukung warga mengakses pelayanan kesehatan dan kesadaran tentang kesehatan yang menjadi kebutuhan mendasar dalam kehidupan masyarakat. Kebijakan tersebut mendapat dukungan dari Badan Zakat Daerah (Bazda) melalui pemberian uang pengganti transpor kepada pasien yang berkunjung ke puskesmas. Pelayanan gratis yang diberikan puskesmas adalah pelayanan kesehatan masyarakat dasar yang berdampak meningkatkan jumlah kunjungan sehingga berpengaruh terhadap kinerja puskesmas, kinerja tenaga kesehatan, dan kepuasan pasien. ${ }^{1-3}$

Implementasi pelayanan gratis dalam penelitian ini diukur dengan peraturan daerah Kota Padang. Kinerja Puskesmas dilihat berdasarkan indikator yang meliputi

Alamat Korespondensi: Iskandar Syah, Dewan Perwakilan Rakyat Daerah Kota Padang, Jl. Sawah No. 50 Padang, Hp. 081266050211, e-mail: iskandarsyahmkes@yahoo.com 
waktu dalam proses, kualitas kerja, pengetahuan, kerja sama. ${ }^{4,5}$ Kinerja tenaga kesehatan dilihat berdasarkan indikator kemampuan dan pengetahuan, inisiatif dan kreativitas, standar profesional, kehadiran.6,7 Kepuasan pasien dilihat berdasarkan indikator kehandalan, kepedulian, jaminan kepastian, perhatian, wujud nyata. ${ }^{8}$ Evaluasi dilihat berdasarkan indikator ketersediaan sarana dan prasarana, program tepat sasaran, pencapaian sumber daya, produktivitas, semangat kerja atau motivasi. ${ }^{9,10}$ Pengembangan model pelayanan adalah model kebijakanan alternatif terbaik, dari implementasi pelayanan kesehatan yang ada pada saat ini.9,11

Mutu pelayanan kesehatan merupakan kinerja yang mencerminkan tingkat kesempurnaan pelayanan kesehatan sehingga dapat menimbulkan kepuasan pasien dan sesuai dengan standar serta kode etik yang telah ditetapkan. ${ }^{12}$ Model kebijakan pelayanan gratis yang dikembangkan adalah model pelayanan yang dapat bermanfaat maksimal bagi semua aspek yang terlibat, meliputi pasien, puskesmas, dan tenaga kesehatan. Kompensasi keadilan diharapkan dapat menjadi penambah semangat kerja dan meningkatkan kesejahteraan dan meningkatkan kondisi kesehatan tenaga kesehatan yang sangat rentan terjangkiti berbagai penyakit infeksi dan penyakit menular yang dijumpai ketika memberikan pelayanan kesehatan kepada pasien. Sistem insentif ini lebih efektif dalam pemeliharaan tenaga kesehatan dengan memotivasi tenaga kesehatan mencapai prestasi kerja yang lebih tinggi. ${ }^{13}$ Tujuan penelitian ini adalah menganalisis kebijakan dan mengembangkan model kebijakan pelayanan gratis di puskesmas Kota Padang.

\section{Metode}

Penelitian ini menggunakan metode kuantitatif dan kualitatif, terhadap kebijakan yang dikeluarkan Pemerintah Kota Padang di bidang pelayanan kesehatan di puskesmas. Pendekatan secara kuantitatif dilakukan terhadap kinerja puskesmas dan kinerja tenaga kesehatan dengan menggunakan data sekunder laporan tahunan Dinas Kesehatan Kota Padang dan laporan puskesmas yang diteliti serta kepuasan pasien atau pelanggan menggunakan kuesioner. Penelitian kualitatif dilakukan dengan metode wawancara mendalam untuk mengetahui kinerja puskesmas dan kinerja tenaga kesehatan serta metode focus group disscussion (FGD) untuk mengetahui kepuasan pasien dan pelanggan. Subjek penelitian adalah enam puskesmas dari 21 puskesmas yang ada di Kota Padang. ${ }^{14}$ Data dikumpulkan dengan metode wawancara mendalam Pemerintah Kota Padang, Kepala Bapeda, Kepala Dinas Kesehatan Kota Padang, enam kepala puskesmas dan 30 tenaga kesehatan, instrumen yang digunakan adalah tape recorder dan kamera video, FGD terhadap 10 orang pasien di enam puskesmas yang diteliti menggunakan instrumen tape recorder dan kam- era video, dan kuesioner untuk penelitian kuantitatif pada 50 orang pasien yang dipilih secara accidental di enam puskesmas yang diteliti. Langkah-langkah dalam analisis meliputi mengorganisir informasi yang diperoleh melalui wawancara dan observasi dengan informan, membaca keseluruhan informasi, membuatkan transkrip dengan mengelompokan/menggabungkan data, membuat uraian rinci tentang pelaksanan program pelayanan gratis di puskesmas Kota Padang yang berpegaruh terhadap kinerja puskesmas, kinerja tenaga kesehatan dan kepuasan pasien. ${ }^{14}$ Selain itu, menetapkan pola dan menentukan hubungan variabel-variabel yang telah ditemui sebagai jawaban dari rumusan masalah dengan mempertimbangkan penelitian yang sudah dilakukan.

\section{Hasil}

Enam puskesmas di Kota Padang yang diteliti meliputi Puskesmas Padang Pasir, Pauh, Lubuk Kilangan, Bungus, Ulak Karang, dan Lubuk Begalung. Dari data sekunder, kinerja puskesmas dan kinerja petugas kesehatan pada setiap puskesmas dari tahun 2008 hingga 2012 mengalami peningkatan jumlah kunjungan pasien sebagai dampak pelaksanaan program pelayanan kesehatan gratis dan pemberian uang transpor (Gambar 1).

Persentase kehadiran petugas kesehatan di enam puskesmas yang berfluktuasi dan tergolong tinggi. Kinerja tenaga kesehatan dapat dilihat dari pelatihan dan tambahan pendidikan yang diperolehnya, peningkatan jumlah petugas atau tenaga kesehatan yang memperoleh penambahan ilmu dan mengikuti pendidikan (Tabel 1).

Hasil wawancara mendalam pada responden terdapat pada Tabel 2. Data kepuasan pasien secara kualitatif dilakukan melalui FGD dengan variabel, indikator dan pertanyaan serta hasil (Tabel 3).

\section{Pembahasan}

Dalam pelaksanaan pelayanan kesehatan, faktor manusia merupakan komponen utama sebagai perencanaan, pelaksanaan, pengendalian, pengawasan, dan evaluasi.

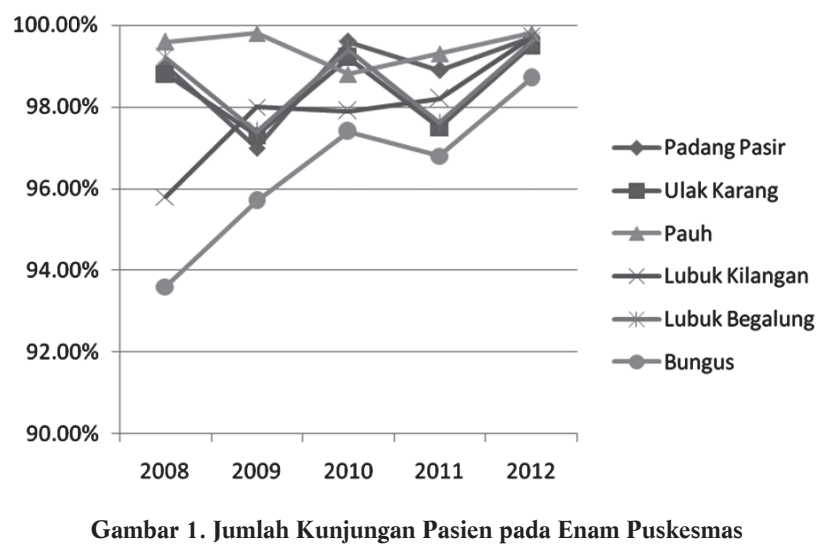


Tabel 1. Persentase Kehadiran Petugas

\begin{tabular}{lcccccc}
\hline Puskesmas & Tahun 2008 (\%) & Tahun 2009 (\%) & Tahun 2010 (\%) & Tahun 2011 (\%) & Tahun 2012 (\%) & Rata-rata \\
\hline Padang Pasir & 99 & 97 & 99,6 & 98,9 & 99,7 & 0,0002 \\
Ulak Karang & 98,8 & 97,3 & 99,2 & 97,5 & 99,5 & 0,0025 \\
Pauh & 99,6 & 99,8 & 98,8 & 99,3 & 99,8 & 0,0005 \\
Lubuk Kilangan & 95,8 & 98 & 97,9 & 98,2 & 99,7 & 0,008 \\
Lubuk Begalung & 99,2 & 97,4 & 99,4 & 97,6 & 99,6 & 0,013 \\
Bungus & 93,6 & 95,7 & 97,4 & 96,8 & 98,7 & 0,008 \\
\hline
\end{tabular}

Sumber : Data Laporan Tahun DKK Padang dan Laporan Puskesmas

Tabel 2. Hasil Matriks Wawancara Mendalam

\begin{tabular}{|c|c|}
\hline Pertanyaan & Hasil \\
\hline Apa yang melatarbelakangi munculnya & Pelayanan kesehatan adalah kebutuhan dasar masyarakat \\
\hline \multirow[t]{2}{*}{ Perda Nomor 05 Tahun 2009? } & Target pemerintah (MDGs 2015) \\
\hline & Instruksi walikota \\
\hline $\begin{array}{l}\text { Bagaimana pelaksanaan Perda } \\
\text { 2009? }\end{array}$ & $\begin{array}{l}\text { Pengobatan gratis pelayanan kesehatan dasar kepada masyarakat Nomor } 05 \text { Tahun } \\
\text { meningkatkan jumlah kunjungan dan kinerja puskesmas }\end{array}$ \\
\hline Bagaimana dengan pemberian uang transpor? & $\begin{array}{l}\text { Bantuan Bazda sangat bermanfaat bagi masya-rakat, tetapi tidak efektif } \\
\text { karena ada pasien yang menyalah artikan pemberian uang transpor }\end{array}$ \\
\hline Bagaimana manfaat program? & $\begin{array}{l}\text { Bermanfaat bagi pasien, terjadi peningkatan jumlah kunjungan sehingga } \\
\text { meningkatkan kinerja petugas dan puskesmas }\end{array}$ \\
\hline Apakah dalam satu hari pelayanan pasien terpenuhi? & Harus dilaksanakan dan selesai dalam satu hari \\
\hline $\begin{array}{l}\text { Bagaimana kualitas kerja, inisiatif, dan kreativitas } \\
\text { petugas berpengaruh pada kinerja puskesmas? }\end{array}$ & $\begin{array}{l}\text { Meningkatkan kegiatan pelayanan kesehatan, melakukan kerjasama sesama } \\
\text { petugas dan meningkatkan motivasi dan semangat kerja }\end{array}$ \\
\hline $\begin{array}{l}\text { Bagaimana pengetahuan, kemampuan dan kerjasama } \\
\text { petugas dalam melaksanakan pelayanan kesehatan } \\
\text { kepada masyarakat? }\end{array}$ & $\begin{array}{l}\text { Petugas bekerja maksimal sesuai SOP, dengan penambahan ilmu sehingga petugas } \\
\text { dapat memberikan pelayanan maksimal, kerjasama petugas kesehatan perlu } \\
\text { binaan dan dimotivasi agar petugas bekerja sesuai tupoksi }\end{array}$ \\
\hline Bagaimana standar operasional kerja petugas? & $\begin{array}{l}\text { Petugas sudah bekerja sesuai standar operasional, prosedur, sesuai kompetensi } \\
\text { dan disiplin ilmu petugas }\end{array}$ \\
\hline Apakah pelaksanaan program sudah tepat sasaran? & $\begin{array}{l}\text { Tidak, karena pasien menyalahartikan pemberian uang transpor, yang merupakan } \\
\text { dampak negatif program }\end{array}$ \\
\hline $\begin{array}{l}\text { Bagaimana dengan ketersediaan sarana dan } \\
\text { prasarana? }\end{array}$ & $\begin{array}{l}\text { Perlu perbaikan sarana prasarana yang membutuhkan alokasi dana pemerintah } \\
\text { yang disesuakan dengan kebutuhan Puskesmas }\end{array}$ \\
\hline $\begin{array}{l}\text { Bagaimana produktivitas, semangat kerja dan } \\
\text { motivasi petugas dalam pelayanan kesehatan? }\end{array}$ & $\begin{array}{l}\text { Petugas tetap bekerja maksimal dan professional dengan ikhlas sesuai dengan } \\
\text { kewajiban, melayani pasien dengan ramah dan sabar serta memupuk kerja sama } \\
\text { sesama petugas kesehatan }\end{array}$ \\
\hline $\begin{array}{l}\text { Bagaimana kepuasan pasien terhadap pelayanan } \\
\text { kesehatan yang diberikan? }\end{array}$ & Sangat bermanfaat dan memuaskan pasien \\
\hline
\end{tabular}

Untuk mewujudkan janji Kepala Daerah tentang pelayanan kesehatan secara gratis, sejak 2 Maret 2009 diberlakukan kebijakan pelayanan kesehatan gratis pada semua semua pasien puskesmas Kota Padang. Kebijakan tersebut diperkuat Peraturan Daerah Nomor 05, tahun 2009 dan didukung uang pengganti transpor Rp2.000 untuk pasien miskin yang berobat ke puskesmas. Uang ini berasal dari zakat PNS Pemko Padang yang dikelola oleh Bazda kota Padang. Hal tersebut membedakan kebijakan pelayanan gratis di Kota Padang dengan di daerah lain.1,2 Kebijakan tersebut memberi kemudahan kepada masyarakat mendapatkan pelayanan kesehatan. Masyarakat sebagian besar menyadari bahwa kesehatan sangat penting dan menyadari kebutuhan hidup sehat. Pemerintah berharap tidak ada lagi halangan masyarakat kurang mampu di Kota Padang memperoleh pelayanan kesehatan yang dibutuhkan.

Tujuan kebijakan program pelayanan kesehatan kota
Padang tersebut telah sesuai target pemerintah yang tertuang dalam MDGs, serta sesuai penjabaran visi dan misi pembangunan kesehatan meningkatkan kesadaran, kemauan dan kemampuan hidup sehat bagi setiap orang agar terwujud derajat kesehatan yang optimal bagi masyarakat dan dapat hidup dengan perilaku dan dalam lingkungan yang sehat, mampu menjangkau pelayanan kesehatan yang bermutu secara adil dan merata untuk mencapai derajat kesehatan masyarakat yang setinggitingginya (Tabel 2). ${ }^{15}$

Di Kota Padang, pelaksanaan kebijakan tersebut berdampak pada peningkatan jumlah kunjungan pasien ke puskesmas (Grafik 1) sehingga meningkatkan kinerja puskesmas dan petugas kesehatan. Sama dengan pelayanan kesehatan gratis di Sukamara, Padang Pariaman, Banjar Baru dan Simalungun, tetapi di kota Padang pelayanan kesehatan gratis diikuti pemberian uang transpor. ${ }^{1-3}$ Kunjungan yang meningkat dengan petugas pela- 
Tabel 3. Hasil Focus Group Disscussion

\begin{tabular}{llll}
\hline Variabel & Indikator & \multicolumn{1}{c}{ Pertanyaan } & \multicolumn{1}{c}{ Kesimpulan } \\
\hline Kepuasan pasien & Kehandalan & Bagaimana kepedulian dan pendekatan & Pelayanan belum sesuai kebutuhan \\
Kofirmasi kuesioner & Kepedulian & petugas dalam pemberian pelayanan? & Ketepatan waktu cukup \\
& Jaminan kepastian & Bagaimana kemudahan pelayanan, tingkat & Informasi kurang \\
& Perhatian & keamanan, kemudahan bertemu dokter? & Kepedulian dan pendekatan kurang \\
& Wujud nyata & Bagaimana perhatian petugas dan & Kemudahan pelayanan kurang \\
& & pendekatan petugas kepada pasien? & Keamanan cukup \\
& Bagaimana pelayanan yang diterima & Kemudahan bertemu dokter cukup \\
& terkait sarana dan prasarana, disiplin & Perhatian dan pendekatan kurang \\
& petugas, kebersihan puskesmas? & Sarana kurang \\
& & Disiplin cukup \\
& & Kebersihan cukup \\
\hline
\end{tabular}

yanan kesehatan yang tetap sama, pelayanan kesehatan kepada pasien harus diselesaikan pada hari yang sama, mempengaruhi kinerja petugas (Tabel 1).1,2,16

Dampak kebijakan pelayanan gratis yang dirasakan petugas kesehatan adalah kesenjangan tugas dan tanggung jawab dengan kesejahteraan karena peningkatan beban kerja tidak sesuai dengan kompensasi keadilan petugas. Bobot kerja dan tuntutan pekerjaan yang bertambah, tuntutan kerja maksimal, membuat tenaga kesehatan perlu mendapatkan kesejahteraan yang lebih baik. Insentif sangat bermanfaat sebagai tambahan penghasilan, menjadikan peningkatan motivasi dan semangat kerja sehingga dapat memberikan pelayanan kesehatan secara maksimal. Keadaan ini sama dengan penelitian di Sukamara, Simalungun, Padang Pariaman. Berbeda dengan di Banjar, pelaksanaan pelayanan gratis diikuti dengan pemberian insentif kepada petugas. Penelitian di Cyprus dan Malawi, pemberian insentif dan dukungan dana meningkatkan mutu pelayanan yang diberikan.2,13 Tenaga kesehatan setiap puskesmas perlu evaluasi program, kelengkapan sarana prasarana, yang sesuai kebutuhan. Kualitas dan kuantitas peralatan yang digunakan memengaruhi prosedur, kecepatan proses sehingga memberikan kepuasan kerja petugas dan memberikan pelayanan yang bermutu sehingga memberikan kepuasan pada pasien.

Ketepatan waktu selama mendapatkan pelayanan kesehatan yang menurut masyarakat cukup, mengindikasikan puskesmas mampu memberikan pelayanan maksimal kepada pasien dengan waktu yang efisiensi. Ketepatan waktu pelayanan juga merupakan salah satu indikator keberhasilan kinerja puskesmas. Namun, kekurangan informasi karena jumlah pasien yang dilayani dalam waktu yang terbatas, menyebabkan tenaga kesehatan tidak dapat memberikan konsultasi dan informasi yang lebih banyak kepada pasien orang perorang sesuai harapan.

Pengembangan model kebijakan adalah suatu sistem yang dibuat untuk mengoptimalkan pencapaian tujuan organisasi sehingga dapat memberikan kebijakan terbaik pada masa mendatang. Model kebijakan pelayanan kesehatan yang disarankan adalah model pelayanan kesehatan dengan manfaat yang dapat dirasakan semua unsur meliputi petugas kesehatan dan pasien. Beberapa alternatif strategis adalah membina kerjasama dengan lintas sektor terkait sektor kesehatan, meningkatkan mutu sumber daya manusia profesional, pelayanan kesehatan yang terjangkau dari aspek fisik dan finansial dan penguatan sumber daya pembiayaan serta pemberdayaan masyarakat.

Pengembangan kebijakan yang ditawarkan menyangkut perbaikan aspek penyandang dana, monitoring dan evaluasi, sarana dan prasarana, serta kompensasi, juga peningkatan mutu layanan. Kebijakan pelayanan kesehatan gratis yang ditawarkan ke Pemerintah Kota Padang adalah penyempurnaan program asuransi kesehatan bagi warga Kota Padang, pembentukan tim khusus penyusun indikator kinerja petugas kesehatan untuk insentif petugas kesehatan berbasis kinerja, melakukan monitoring dan evaluasi program.

Pengembangan model juga memerlukan perencanaan, peningkatan dan pengembangan kualitas sumber daya manusia (SDM) melalui pendidikan lanjutan, pelatihan dan seminar terkait kompetensi setiap petugas, perlu pembinaan dan pengawasan pelaksanaan program di lapangan agar kerjasama dan motivasi kerja petugas tetap terjaga, perlu reward dan punishment berbasis kompensasi atas kinerja, agar SDM yang terlibat lebih termotivasi memberikan kinerja terbaik, dan perlu memperbesar porsi pengalokasian anggaran dana untuk meningkatkan mutu layanan, seperti kelengkapan pengadaan sarana prasarana, dan pelatihan interpersonal komunikasi petugas.

\section{Kesimpulan}

Peraturan Daerah Nomor 05 tahun 2009 tentang kebijakan pelayanan kesehatan gratis di kota Padang merupakan wujud dari janji kepala daerah untuk memberikan masyarakat kemudahan mendapatkan pelayanan kesehatan. Pelaksanaan program pelayanan kesehatan gratis 
disertai pemberian uang transpor pada masyarakat di Kota Padang, hanya menambah jumlah kunjungan dan beban kerja puskesmas serta beban kerja tenaga kesehatan tanpa peningkatan mutu pelayanan. Berdasarkan informasi, pelayanan kesehatan gratis dan pemberian uang transport tersebut, tidak tepat sasaran karena pasien hanya mengejar uang transpor. Ditemukan model baru untuk pelayanan kesehatan gratis yang melibatkan penyandang dana, kompensasi untuk kinerja petugas dan monitoring evaluasi atas kebijakan yang ditimbulkan. Perlu dilakukan penelitian kuantitatif dengan metode survei pada penduduk sasaran yang lebih luas.

\section{Daftar Pustaka}

1. Mustika DG. Analisis karakteristik dan perilaku pembelian masyarakat sebagai dasar penyusunan upaya pemasaran instalasi rawat jalan di Rumah Sakit Darmo Surabaya. Journal Administrasi Kebijakan Kesehatan. 2008; 6 (3): 177-82.

2. Lamsidi A, Hasan BM, Lazuardi L. Evaluasi kinerja puskesmas pelayanan kesehatan dasar gratis di Kabupaten Sukamara tahun 2007 [Tesis]. Yogyakarta: Universitas Gadjah Mada; 2009.

3. Rahmaniah OM, Dewi J. Mutu puskesmas [Tesis]. Yogyakarta: Universitas Gadjah Mada; 2008.

4. Sawang S. Key performance indicators for innovator implementation: perception vs actual usage. Asia Pacific Management Review. 2011; 16 (1): 23-9.

5. Razzaque A, Maria KM. A quantifiable transcultural knowledge management model to improve quality of healthcare: a case study of The Kingdom of Bahrain. Journal of Economic Development, Management, IT Finance and Marketing. 2010; 2(1): 111-49.

6. Castel NG. Quality improvement and top management in nursing homes. Journal Of Quality Management. 1999; 4(1): 95-109.

7. Smith DKM. Increasing employee productivity, job satisfaction and or- ganizational commitment, hospital and health services administration. 1993; 41(2): 160-75.

8. Parasuraman A, Zithalm V, Benryl. Servqual: a multiple item scale for measuring coinsumer perception of service quality. J Retail [serial on internet]. 1988 [cited 2013 Jan 5]; 64(1): 12-41. Available from: http://connection.ebscohost.com/c/articles/6353339/servqual_multiple_item_ scale_measuring_consumer_perceptions_service_quality.

9. Ishak MIM, Suhaida MS, Yuzaine MY. Performance measurement indicators for academic staff in Malaysia private high education institutions: a case study in united [article on internet]. 2007 [cited 2013 Feb 13]. Available from: www.researchgate.net/publication/242174198_PERFORMANCE_MEASUREMENT_INDICATORS_FOR_ACADEMIC_S TAFF_IN_MALAYSIA_PRIVATE_HIGHER_EDUCATION_INSTITUTIONS_A_CASE_STUDY_IN_UNITED.

10. Abodunrin OL, Akande TM. Knowledge and perception of a health and telemedicine among health professionals in LAUTECH teaching hospital, Osogno, Nigeria. International Journal of Health Research. 2009; 2(1): 51-8.

11. Babakus E, Craven DW, Johnston M, Wiliam C. Examining the role of organizational variables in the sales person job satisfaction model. Journal of Personal Selling and Sales Management. 1996; 16(3): 7-26.

12. Karassavidou E, Glavel N. Assessing the program of quality initiatives in hospital throught clinical governance. Proceedings of the10 th Toulon - Verona Conference on Quality in Services, Palermo, Italy. 2007.

13. Makoka D, Kaluwa B, Kambewa P. Demand for private health insurance whene public health services are free : the case of Malawi. Journal of Applied Sciencess. 2007; 7(21): 3268-73.

14. Moleong LJ. Metodologi penelitian kualitatif. Bandung: PT Remaja Rosdakarya Bandung; 2011.

15. Dinas Kesehatan Kota Padang. Laporan profil kesehatan tahun 2009. Padang: Dinas Kesehatan Kota Padang; 2010.

16. Dinas Kesehatan Kota Padang. Profil kesehatan tahun 2008. Padang: Dinas Kesehatan Kota Padang; 2009. 